\title{
Dielectrophoretic Field-Flow Microchamber for Separation of Biological Cells Based on Their Electrical Properties
}

\author{
Jaka Čemažar, Danilo Vrtačnik, Slavko Amon, Member, IEEE, and Tadej Kotnik*
}

\begin{abstract}
We describe the development, fabrication and testing of a microfluidic chamber for dielectrophoretic field-flow separation of biological cells based on their electrical properties. The chamber was constructed from a single Pyrex wafer with interdigitated Au electrodes, a spacer, and a top cover glass, making the events in the chamber observable under most optical microscopes. The dimensions were optimized based on numerical computations of the electric field, its gradient and the fluid-flow velocity profile. The electrodes were fabricated using photolithography. A double-sided self-adhesive tape of $100 \mu \mathrm{m}$ thickness was used as a spacer, with an opening of $80 \mathrm{~mm}$ length and $20 \mathrm{~mm}$ width cut in its middle to form a channel of $100 \mu \mathrm{m}$ height, and with water-resistant acrylic glue of the tape holding the glass plates together and providing a tight seal. The glue loses its adhesive properties above $70{ }^{\circ} \mathrm{C}$, allowing for easy disassembly of the chamber in hot water and its thorough cleaning. A 1:1 mixture of normal and $50{ }^{\circ} \mathrm{C}$-heat-treated $\mathrm{CHO}$ cells was used to test the chamber. A $93 \%$ efficiency of separation was obtained, confirming the usefulness of the chamber in separating cells with sufficient differences in electrical properties of their membranes.
\end{abstract}

Index Terms - Cell separation, dielectrophoresis, field-flow fractionation, microchamber.

\section{INTRODUCTION}

D IELECTROPHORESIS is the motion of uncharged polarizable particles in a nonuniform electric field [1]. Electric field induces a dipole moment of the particles, and the inhomogeneity of the field results in a net force on each particle (i.e., the time average of the force is not zero). Dielectric force depends on the electric properties of the particles and the surrounding medium, and can be directed either towards higher electric field (if the particle is more polarizable than the medium) or towards lower field (if the particle is less polarizable).

Dielectrophoresis in ac electric fields with frequencies in the $\mathrm{kHz}$ and $\mathrm{MHz}$ range is a useful method for manipulation of biological cells, because in such fields the undesired (and often detrimental for the cells) electrochemical processes on the surface of the electrodes are almost entirely eliminated, while in dc fields they are always present [2].

Manuscript received July 20, 2010; revised December 16, 2010; accepted March 08, 2011. Date of current version April 27, 2011. This work was supported by the Slovenian Research Agency (Research Program P2-0249). Asterisk indicates corresponding author.

J. Čemažar, D. Vrtačnik, and S. Amon are with the Faculty of Electrical Engineering, University of Ljubljana, Ljubljana 1000, Slovenia

*T. Kotnik is with the Faculty of Electrical Engineering, University of Ljubljana, Ljubljana 1000, Slovenia.

Digital Object Identifier 10.1109/TNB.2011.2128340
Common uses of dielectrophoresis are in selective cell manipulation, separation of particles, ranging from DNA fragments to eukaryotic cells [3], [4], and cell properties characterization [5], [6]. Separation of cells by dielectrophoresis is possible if the cells in the mixture belong to two (or more) classes, each with either a different geometry or different dielectric permittivity and/or electric conductivity [7], [8]. Different geometrical and electrical properties result in different dielectrophoretic force $\left(F_{\mathrm{DEP}}\right)$ acting on the cells of each class. The size of $F_{\mathrm{DEP}}$ also depends on the frequency $\nu$ of the electric field by which dielectrophoresis is generated, and the plot of $F_{\mathrm{DEP}}(\nu)$ is termed the dielectrophoretic spectrum. Thus, by exposing the mixture to the ac field with the frequency at which the difference between $F_{\mathrm{DEP}}$ acting on the cells in the two classes is sufficiently large, spatial separation of the two classes can be achieved.

In the past years a number of systems for dielectrophoretic separation of cells were developed. Based on their principle of functioning, they can in general be divided into two groups: the systems in the first group are based on opposite directions of $F_{\text {DEP }}$ acting on the two classes of cells, and the systems in the second group on different magnitudes of $F_{\mathrm{DEP}}$ [9], [10].

The systems based on opposite directions of $F_{\mathrm{DEP}}$ are useful for separating cells with considerable differences in electrical properties of their plasma membrane, e.g., living cells from dead ones [11]-[13], or normal cells from cancerous or infected ones [7], [14]-[18]. Still, even for cells with substantially different membrane properties, the efficiency of this method can be hampered if the cells within one or both classes have a broad distribution of sizes. Namely, as (1)-(3) in Section II-B show, the magnitude of $F_{\mathrm{DEP}}$ is roughly proportional to $r^{3}$; in (1) the term $r^{3}$ features directly, while in (3) the two fractions containing $r$ have values close to 1 (as $r \gg d$ ).

In the systems based on different magnitudes of $F_{\mathrm{DEP}}$, dielectrophoresis is combined with a flow of the medium in which the cells are suspended (the buffer). As we describe in more detail below, these systems largely overcome the two weaknesses of the systems based on opposite directions of $F_{\mathrm{DEP}}$ : they are much less sensitive to differences in cell size, and are also useful with smaller differences in electrical properties of the cells [8]. In this method, often referred to as field-flow fractionation [9], [11], [15], [16], [19]-[26], separation is based on the balance between the dielectrophoretic force and effective gravitational force (i.e., the total gravitational force decreased by the buoyancy force in the medium). In general, the electrodes are situated at the bottom of the channel through which the suspension 
(a)
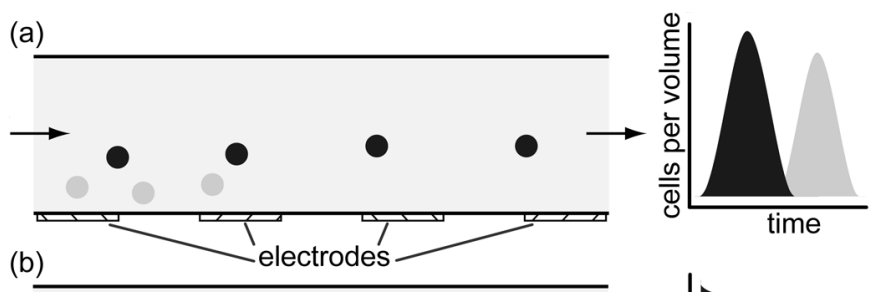

(b)
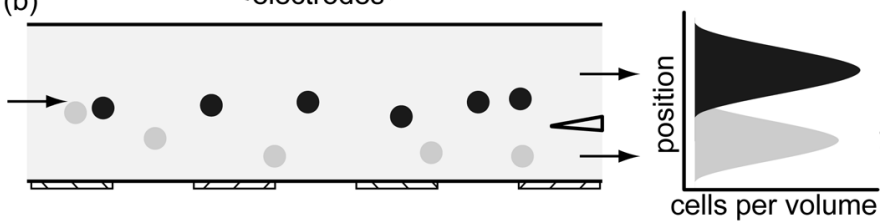

Fig. 1. Dielectrophoretic field-flow fractionation. (a) Temporal separation. A small amount of cell suspension is pumped through the chamber and the cells with equilibrium heights closer to the vertical center reach the output before the cells farther away. (b) Spatial separation. The cells are pumped through the chamber continuously, and separated at the output by the vertical separators (only one is shown here).

is pumped, and the applied electric field frequency and properties of the buffer are such that dielectrophoresis is negative and $F_{\mathrm{DEP}}$ acting on cells is oriented roughly upwards (i.e., towards lower field). As the gravitational force is proportional to the mass of the cell and thus roughly to $r^{3}$, and the oppositely directed $F_{\text {DEP }}$ is also roughly proportional to $r^{3}$ (see the preceding paragraph), this reduces the dependence of the separation on cell size considerably.

The channel height in field-flow fractionation chambers ranges from tens to hundreds of micrometers, and the typical channel length is several centimeters. This ensures that the flow is laminar and has a parabolic velocity profile. Since the cells have a slightly higher density than the surrounding buffer, the gravitational force pulls them towards the bottom of the chamber, but as they move closer to the electrodes this simultaneously results in an increasing $F_{\text {DEP }}$, while the gravitational force remains constant. In this manner, each cell acquires a vertical position in which the two forces are in equilibrium. Due to the parabolic flow profile, cells at different vertical position within the channel have different velocities, with the cells at the middle of the channel height flowing the fastest and reaching the chamber output first, and with the cells levitating near the bottom or near the top flowing the slowest and coming out last.

The described mechanism can be used for separation in two ways. In temporal separation, a batch of the cell suspension is injected into the channel and pumped through it at a constant rate (volume per unit time). As the distinct classes of cells are separated vertically, the parabolic vertical distribution of velocities results in the cells of different classes reaching the chamber output at different times [Fig. 1(a)]. If the containers at the output are interchanged at appropriate times, the distinct classes of the cells can be collected each into its separate container.

In spatial separation, the chamber output contains one or several vertical separators that split the flow. Thus, the cells belonging to several classes can be collected into their containers simultaneously, and with new batches of cells injected into the channel, the process can continue indefinitely [27] [Fig. 1(b)].

Still, the three-dimensional structures required in such spatial separation chambers make them more difficult to manufacture. Moreover, in typical designs the parts of the chamber are bonded together permanently, so that disassembling and reassembling the chamber is not possible, which also makes it hard to clean the chamber thoroughly. On the other hand, as temporal separation requires a substantial horizontal splitting of the two classes in order to be efficient, the channel in such chambers has to be much longer than in the spatial separation chambers, in which the cells only need to acquire their equilibrium heights to be collected into the proper container. Thus, in spatial separation chambers, the channel can be as short as $6 \mathrm{~mm}$ [11], while for temporal separation, the shortest useful channels are in the range of 15-25 $\mathrm{mm}$ [9], [21], [23].

As the resolution of temporal separation increases with the channel length, this in general provides the motivation for design of chambers as large as technically feasible, and a prototype with a channel as long as $388 \mathrm{~mm}$ has been reported [15]. However, the increase in channel length and thereby resolution is accompanied by increasing difficulty of manufacturing the electrodes on a single wafer or substrate. As a consequence, large chambers are typically built from several segments glued or bonded together, which introduces the problem of assembling, disassembling, and cleaning also to the temporal separation chambers.

In this article we describe the development and manufacturing of a temporal separation chamber with a channel $80 \mathrm{~mm}$ long, $20 \mathrm{~mm}$ wide, and $100 \mu \mathrm{m}$ high. The bottom surface of the chamber was made from a single Pyrex glass wafer on which an array of 400 interdigitated electrodes was deposited by photolithography. The top surface was also made from glass, which allows for monitoring of the events in the chamber both from the top and from the bottom (between the electrodes). The top and bottom glass are attached to each other by a double-sided self-adhesive tape $100 \mu \mathrm{m}$ thick and containing an opening that forms the channel. This provides both a tight seal and a fixed and controlled channel height. At the same time, this simple design allows for easy assembly, disassembly, and cleaning of the chamber. The efficiency of our separation chamber was tested by separating normal mammalian cells from ones heat-treated at $50{ }^{\circ} \mathrm{C}$.

\section{MATERIALS AND Methods}

\section{A. Computation of Electric Field and Its Gradient}

The separation chamber was designed in COMSOL Multiphysics 3.5a finite-element analysis software package (Comsol $\mathrm{AB}$, Stockholm, Sweden). Computation of the spatial distribution of the electric field strength and its gradient at various electrode and gap widths was performed by solving the Laplace equation in the ac/dc module of this package [28], [29]. The velocity profile of the buffer flow through the chamber was computed by solving the Navier-Stokes equations for an incompressible laminar flow [28].

\section{B. Computation of Dielectrophoretic Force}

The computation of dielectrophoretic force was based on the single-shell spherical model of a cell as derived in [30], with the vector of the force given by

$$
\mathbf{F}_{\mathrm{DEP}}=2 \pi r^{3} \varepsilon_{\mathrm{e}} \operatorname{Re}\left[f_{\mathrm{CM}}\right] \operatorname{grad}\left(|\mathbf{E}|^{2}\right),
$$


TABLE I

The Radius, Membrane Thickness, Electric Conductivities AND Dielectric Permittivities of Normal and Heat-Treated CElls AND The Surrounding Medium. The VAlues of $\sigma_{\mathrm{e}}$ AND $\varepsilon_{\mathrm{e}}$ ARE Those of The Phosphate Buffer Saline Composed as Described In SEction II.E. For the Comment on [34] Marked By an Asterisk; SEe the MaIn TeXT

\begin{tabular}{|l|l|c|l|l|}
\hline & unit & normal & $\begin{array}{l}\text { heat- } \\
\text { treated }\end{array}$ & source \\
\hline$r$ & $\mathrm{~m}$ & $5.9 \times 10^{-6}$ & $5.4 \times 10^{-6}$ & measured \\
\hline$d$ & $\mathrm{~m}$ & \multicolumn{2}{|c|}{$4 \times 10^{-9}$} & {$[31]$} \\
\hline$\sigma_{\mathrm{e}}$ & $\mathrm{S} / \mathrm{m}$ & \multicolumn{2}{|c|}{0.03} & measured \\
\hline$\varepsilon_{\mathrm{e}}$ & $\mathrm{As} / \mathrm{Vm}$ & \multicolumn{2}{|c|}{$6.9 \times 10^{-10}$} & {$[32]$} \\
\hline$\sigma_{\mathrm{m}}$ & $\mathrm{S} / \mathrm{m}$ & $3 \times 10^{-7}$ & $1.5 \times 10^{-6}$ & {$[33],[34]^{*}$} \\
\hline$\varepsilon_{\mathrm{m}}$ & $\mathrm{As} / \mathrm{Vm}$ & \multicolumn{2}{|c|}{$6.2 \times 10^{-11}$} & {$[35]$} \\
\hline$\sigma_{\mathrm{i}}$ & $\mathrm{S} / \mathrm{m}$ & \multicolumn{2}{|c|}{0.5} & {$[36]$} \\
\hline$\varepsilon_{\mathrm{i}}$ & $\mathrm{As} / \mathrm{Vm}$ & \multicolumn{2}{|c|}{$5.3 \times 10^{-10}$} & {$[35]$} \\
\hline
\end{tabular}

with

$$
f_{\mathrm{CM}}=\frac{\varepsilon_{\mathrm{c}}^{\prime}-\varepsilon_{\mathrm{e}}^{\prime}}{\varepsilon_{\mathrm{c}}^{\prime}+2 \varepsilon_{\mathrm{e}}^{\prime}}
$$

and

$$
\varepsilon_{\mathrm{c}}^{\prime}=\varepsilon_{\mathrm{m}}^{\prime} \frac{\left(\frac{r}{r-d}\right)^{3}+2 \frac{\varepsilon_{\mathrm{i}}^{\prime}-\varepsilon_{\mathrm{m}}^{\prime}}{\varepsilon_{\mathrm{i}}^{\prime}+2 \varepsilon_{\mathrm{m}}^{\prime}}}{\left(\frac{r}{r-d}\right)^{3}-\frac{\varepsilon_{\mathrm{i}}^{\prime}-\varepsilon_{\mathrm{m}}^{\prime}}{\varepsilon_{\mathrm{i}}^{\prime}+2 \varepsilon_{\mathrm{m}}^{\prime}}}
$$

with

- $|\mathbf{E}|:$ the amplitude of the applied ac electric field with frequency $\nu$,

- Re $\left[f_{\mathrm{CM}}\right]$ : the real part of the Clausius-Mossotti factor;

$-r$ : the cell radius;

$-d$ : the membrane thickness;

- $\varepsilon_{\mathrm{e}}^{\prime}, \varepsilon_{\mathrm{m}}^{\prime}, \varepsilon_{\mathrm{i}}^{\prime}$ : the complex dielectric permittivities of the external medium, membrane, and the cell interior (cytoplasm), respectively, each given by $\varepsilon^{\prime}=\varepsilon-\mathrm{j} \sigma /(2 \pi \nu)$, where $\varepsilon$ and $\sigma$ are the dielectric permittivity and the electric conductivity of the region.

Equations (1)-(3) are accurate for cells in suspensions (as they are roughly spherical), provided that they are sufficiently far from each other (i.e., in dilute suspensions) as well as from the electrodes [2], [30].

Table I specifies the values of the geometric and electric parameters featuring in (1)-(3) as they were used in our analysis. It should be noted that the electric parameters of the cell membrane and the cytoplasm are taken from reported measurements on erythrocytes, leukocytes, and yeast cells, as to our knowledge no such measurements have yet been published for $\mathrm{CHO}$ cells. Still, as the major lipid and protein membrane constituents are similar for most cell types, and so is the ionic composition of the cytosol, it seems safe to assume that the electric parameters in Table I are applicable, at least to the order of magnitude, also to $\mathrm{CHO}$ cells. Furthermore, in a study on yeast cells, Huang et al. [34] have estimated that heat-treatment at $75^{\circ} \mathrm{C}$ can increase the membrane conductivity by a factor of about 500 , but since our heat-treatment was performed at a much more moderate temperature of $50{ }^{\circ} \mathrm{C}$, we assumed a conservative factor of 5 . (a)

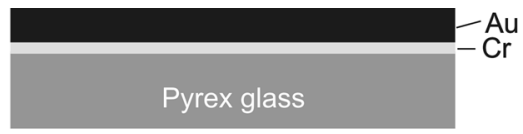

(b)

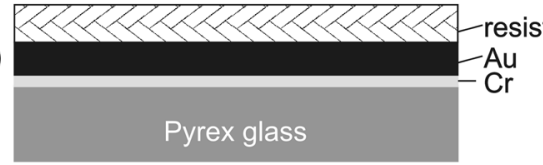

(c)

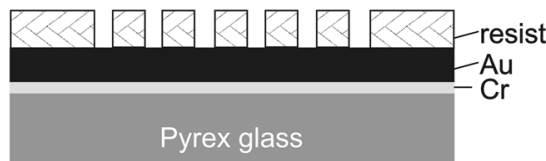

(d)

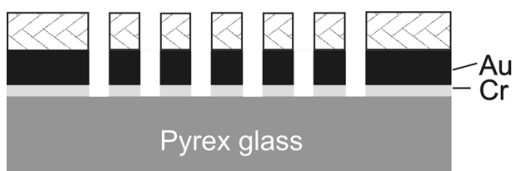

(e)

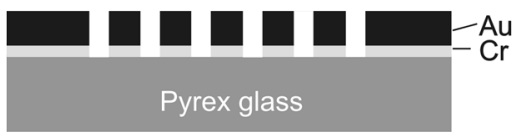

Fig. 2. Fabrication of the electrodes. (a) Deposition of chromium and gold by sputtering. (b) Spin-on of the photoresist. (c) Development of the photoresist. (d) Wet-etching of the metallic layers. (e) Removal of the photoresist.

$\mathbf{F}_{\text {DEP }}$ as given by (1)-(3) was computed in Matlab (Mathworks, Natick, MA), with the electric field gradient precomputed in COMSOL Multiphysics 3.5a (see Section II-A). For relatively dense suspensions and for cells near the electrodes, a more accurate estimate was obtained by numerical computation of the Maxwell stress tensor in COMSOL Multiphysics 3.5a as available for postprocessing in the ac/dc module.

\section{Fabrication of Electrodes}

The fabrication of the electrodes was based on photolithography, and the complete process is outlined in Fig. 2. The mask was drawn in ZWCAD 2009 (ZWCAD Software Co., Guangzhou, China) and printed on Creo Scitex Dolev 800 imagesetter (Creo Inc., Burnaby, Canada; now part of Eastman Kodak Co., Rochester, NY). The starting material was Pyrex 7740 both sides mechanically polished $(\mathrm{Ra}<1.5 \mathrm{~nm})$ wafer of $100 \mathrm{~mm}$ diameter and $700 \mu \mathrm{m}$ thickness (Corning Inc., Corning, $\mathrm{NY}$ ). After wet chemical cleaning of the Pyrex substrate in the $\mathrm{SC} 1$ solution $\left(\mathrm{NH}_{4} \mathrm{OH}: \mathrm{H}_{2} \mathrm{O}_{2}: \mathrm{H}_{2} \mathrm{O}\right.$ in $1: 1: 5$ ratios) at $75^{\circ} \mathrm{C}$ for $10 \mathrm{~min}$, the metal sandwich of $\mathrm{Cr}$ and $\mathrm{Au}$, with $50 \mathrm{~nm}$ and $150 \mathrm{~nm}$ thicknesses respectively, was deposited by sputtering. The photoresist layer (HPR 504, Arch Chemicals, Norwalk, CT) was then spun-on onto the metal-covered substrate surface, patterned, developed and hard baked at $120{ }^{\circ} \mathrm{C}$. This process was followed by wet chemical etching of thin $\mathrm{Au}$ and $\mathrm{Cr}$ layers. Finally, stripping of the photoresist layer at $60{ }^{\circ} \mathrm{C}$ for $30 \mathrm{~min}$ in AZ100 Remover (MicroChemicals GmbH, Ulm, Germany) completed the fabrication of the electrodes.

\section{Other Chamber Components}

The top surface of the chamber was made of soda-lime glass of $100 \mathrm{~mm}$ length, $50 \mathrm{~mm}$ width and $2 \mathrm{~mm}$ thickness (Omahen d.o.o., Ljubljana, Slovenia). The holes through the top surface were drilled with a $2 \mathrm{~mm}$ diameter diamond drill bit using 
the Dremel 398 drill (Dremel Europe B.V., Breda, The Netherlands). The double-sided self-adhesive tape (Isotrade Jereb k.d., Slovenia) was $50 \mathrm{~mm}$ wide, $100 \mu \mathrm{m}$ thick, and made of biaxially oriented polypropylene (BOPP), with nontoxic water-resistant acrylic glue.

\section{E. Cell Culturing and Preparation}

Chinese hamster ovary $\mathrm{CHO}$ cells (European Collection of Cell Cultures, Salisbury, U.K.) were grown in two culture flasks (TPP AG, Trasadingen, Switzerland) in Ham's F-12 culture medium (PAA Laboratories GmbH, Pasching, Austria) supplemented with $2 \mathrm{mM}$ glutamine (Sigma-Aldrich Corp., St. Louis, MO), $10 \%$ fetal bovine serum (PAA Laboratories $\mathrm{GmbH}$ ) and antibiotics crystacillin (Pliva, Zagreb, Croatia), gentamycin (Sigma-Aldrich Corp.) at $37{ }^{\circ} \mathrm{C}$ in a humidified $5 \% \mathrm{CO}_{2}$ atmosphere.

In the first flask, the cells were labeled fluorescently with CellTracker Orange CMRA (Invitrogen, Carlsbad, CA) following manufacturer's protocol and detached from the flask surface by trypsination in $0.25 \%$ trypsin/EDTA (Sigma-Aldrich Corp.). The obtained suspension was centrifuged for $5 \mathrm{~min}$ $\left(1000 \mathrm{rpm}\right.$ at $\left.4{ }^{\circ} \mathrm{C}\right)$, resuspended in an isoosmotic phosphate buffer saline prepared as in Usaj et al. [37] and diluted with 250 $\mathrm{mM}$ sucrose buffer to adjust the conductivity to $27 \mathrm{mS} / \mathrm{m}$ at preserved isoosmolarity. The suspension was again centrifuged and resuspended in the buffer of same composition at final concentration of $2 \times 10^{6} \mathrm{cells} / \mathrm{ml}$. This yielded a suspension of fluorescently labeled living cells.

In the second flask, the protocols of trypsination and preparation of cell suspension were the same as in the first flask, except that fluorescent labeling was not performed, and before the two centrifugations, the cells were heat-treated in the culture medium by placing the vial with the cell suspension into a water bath at $50{ }^{\circ} \mathrm{C}$ for $15 \mathrm{~min}$. This yielded a suspension of unlabeled cells that showed no long-term viability.

The two cell suspensions were mixed together in a 1:1 ratio to obtain a mixture of living and dead cells for subsequent separation in the chamber.

\section{F. Testing of the Separation Chamber}

Voltage of $6 \mathrm{~V}$ peak-to-peak amplitude at $65 \mathrm{kHz}$ was delivered to the electrodes of the chamber by a function generator (33250A, Agilent Technologies, Inc., Santa Clara, CA). Silicon tubes with $1.5 \mathrm{~mm}$ inside diameter (Graupner $\mathrm{GmbH} \&$ Co. KG, Stuttgart, Germany) were connected to the chamber and a $1 \mathrm{ml}$ syringe (Monoject, Kendall, Mansfield, MA, USA) mounted onto the syringe pump (Aladdin, WPI Inc., Boulevard Sarasota, FL). The flow of cell suspension through the channel was monitored on Axiovert 200 inverted microscope (Carl Zeiss MicroImaging $\mathrm{GmbH}$, Göttingen, Germany) equipped with a cooled CCD video camera VisiCam 1280 (Visitron Systems $\mathrm{GmbH}$, Munich, Germany) and MetaMorph 7.0 image acquisition software (Molecular Devices, Sunnyvale, CA). The sequence of images taken at $6 \mathrm{fps}$ was used to calculate the velocity of individual cells and to estimate their equilibrium height (vertical position within the channel). The samples collected at the output of the separation chamber were analyzed using the same combination of microscope, camera, and acquisition software, with the total number of cells counted in phase-contrast images, and the number of living cells in fluorescence images. The final separation results were pooled from 4 independent experiments.

\section{RESULTS AND DISCUSSION}

\section{A. Computer-aided Chamber Design}

As (1) shows, the dielectrophoretic force is proportional to the gradient of the square of the electric field. For efficient field-flow fractionation, the channel height, electrode dimensions, and the applied electric field amplitude should be chosen in a manner that provides a significant vertical variation of the field gradient in the channel. This assures that cells with different electric properties will attain different equilibrium heights, and thus different horizontal velocities in the flow. Still, due to the parabolic flow velocity profile, two classes of cells with rather distinct electric properties could attain similar horizontal velocities, provided that the two classes would have similar equilibrium distances from the vertical center, one above and the other below it. To avoid this, significant vertical variation of the field gradient should be limited to the bottom half of the channel, making both the dielectrophoretic force in the upper half of the channel and its variation there small. With the designs in which the electrodes are confined to the bottom surface of the channel, this requirement is not difficult to achieve, as the field gradient decreases rapidly with the distance from the electrodes, and it suffices to choose an adequate channel height for given electrode dimensions and given range of field amplitudes to be used.

Numerical parametrization shows that the best results are obtained if the electrode width and the interelectrode gap are of similar size. Namely, as seen in Fig. 3, the variation of $\operatorname{grad}\left(|\mathbf{E}|^{2}\right)$ - and thus also of $\mathrm{F}_{\mathrm{DEP}}$ - along the channel at any fixed height is much smaller in this case than if the differences between the electrode width and interelectrode gap are large (note the logarithmic vertical scale).

Fig. 3(b) shows that for chambers in which the electrode width is similar to the interelectrode gap, $\left|\operatorname{grad}\left(|\mathbf{E}|^{2}\right)\right|$ at vertical heights exceeding one-half of the electrode width is very small compared to its largest values at heights closer to the bottom. This is also seen in Fig. 4, which shows the complete spatial distribution of $\left|\operatorname{grad}\left(|\mathbf{E}|^{2}\right)\right|$ in the channel analyzed in Fig. 3(b). As a consequence, the chamber design requirement that the cells should not attain equilibrium positions above the vertical center of the channel is met if the channel height does not exceed the electrode width.

\section{B. Selection of Materials and Chamber Assembly}

To allow for monitoring of the separation process in the chamber, both the top and the bottom of the channel were made of glass; from the bottom, the monitoring is possible through the interelectrode gaps. The Pyrex glass used for the bottom of the channel withstands the high temperatures of the photolithographic electrode fabrication (see Section II-C), while the soda-lime glass used for the top is inexpensive and resistant to moderate mechanical stress. The golden electrodes are chemically inert and resistant to corrosion, but as with any 
(a) $\quad x[\mathrm{~mm}]$

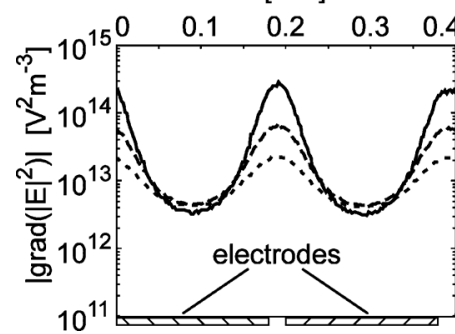

(b) $\quad x[\mathrm{~mm}]$

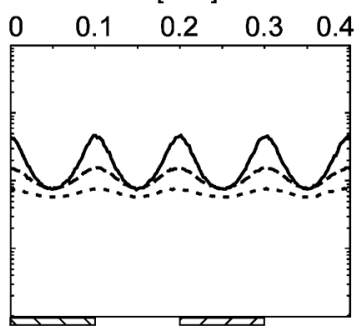

(c) $\quad x[\mathrm{~mm}]$

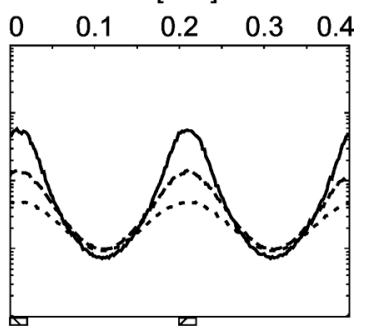

Fig. 3. Variation of $\log \left(\left|\operatorname{grad}\left(|\mathrm{E}|^{2}\right)\right|\right)$ along the channel at three different ratios between the electrode width and interelectrode gap: (a) $180 \mu \mathrm{m}: 20 \mu \mathrm{m}$ (ratio 9:1), (b) $100 \mu \mathrm{m}: 100 \mu \mathrm{m}$ (1:1), (c) $20 \mu \mathrm{m}: 180 \mu \mathrm{m}$ (1:9). In all three cases, the chamber height is $100 \mu \mathrm{m}$, while the three curves show grad(|E| $\left.\left.\right|^{2}\right)$ at $20 \mu \mathrm{m}$ (solid), $35 \mu \mathrm{m}$ (dashed), and $50 \mu \mathrm{m}$ (dotted) from the bottom of the chamber. The computations were performed in COMSOL Multiphysics.

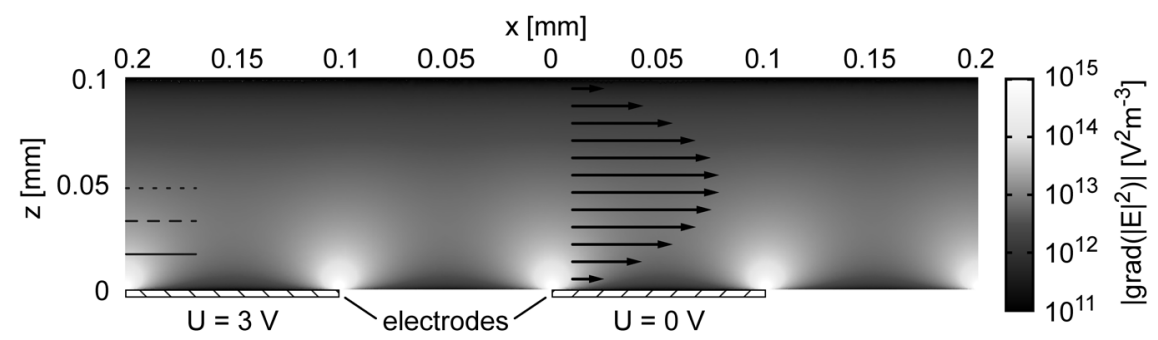

Fig. 4. Variation of $\log \left(\left|\operatorname{grad}\left(|E|^{2}\right)\right|\right)$ along the channel with electrode width, interelectrode gap, and channel height of $100 \mu \mathrm{m}$ each. The solid, dashed and dotted horizontals mark the lines along which the three corresponding curves in Fig. 3(b) are plotted. The arrows show the flow velocity profile as a function of vertical position within the channel. All the computations were performed in COMSOL Multiphysics.

electrodes made of metal, delivery of substantial direct current should be avoided to prevent their electrolytic dissolution. The layer of chromium between the glass and the layer of gold ensures stable adhesion.

The channel length was set at $80 \mathrm{~mm}$ (limited by the $100 \mathrm{~mm}$ diameter of the circular Pyrex 7740 wafer and by the photolithographic procedure), and the channel width at $20 \mathrm{~mm}$. With 100 $\mu \mathrm{m}$ channel height, this resulted in the total channel volume of $160 \mu \mathrm{l}$. With typical (dilute) cell suspensions containing millions of cells per ml, this allows for separation of a batch containing tens of thousands of cells.

For controlled experiments, the spacer should provide a fixed and well-defined channel height, and we tested $100 \mu \mathrm{m}$ sheets of several materials for this purpose. With Teflon, latex, and polyolefin/paraffin (Parafilm) sheets, a tight seal can only be achieved if the glass-spacer-glass sandwich is pressed together rather strongly and uniformly (e.g., by an adequate array of clamps). However, the large pressures applied can deform the spacer and affect its thickness, and they can also cause one or even both of the glass surfaces to break. In our chamber, we thus finally opted for a $100 \mu \mathrm{m}$ thick double-sided self-adhesive tape made of biaxially oriented polypropylene (BOPP), with nontoxic acrylic glue. The tape width was $50 \mathrm{~mm}$, and the channel was made by cutting an $80 \mathrm{~mm} \times 20 \mathrm{~mm}$ opening in the center of a $100 \mathrm{~mm} \times 50 \mathrm{~mm}$ chunk of the tape. Both the BOPP and the acrylic glue are water resistant, thereby providing a reliable and tight seal for the glass-spacer-glass sandwich. At temperatures above $70^{\circ} \mathrm{C}$, however, the acrylic glue loses its adhesive properties, which allows for easy disassembly of the sandwich in hot water, and the remaining traces of glue on the glass surfaces can then be removed by ethanol or acetone. A new chunk of tape must thus be used as a spacer every time the chamber is disassembled and reassembled, but the cost of this is rather negligible.

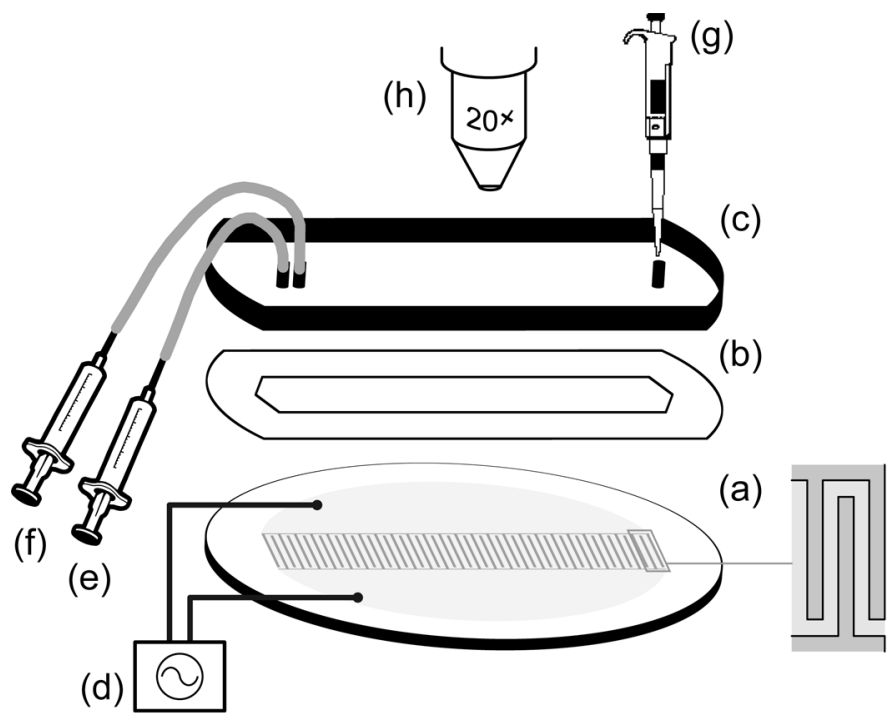

Fig. 5. The separation chamber and supplementary experimental equipment: (a) Pyrex wafer with the electrodes, (b) spacer, (c) top glass surface, (d) electric field generator, (e) syringe with pure buffer, (f) syringe with the suspension of cells, (g) pipette for collecting the samples at the chamber output, (h) microscope for monitoring of the events within the chamber.

The chamber made as described above is only $2.8 \mathrm{~mm}$ thick, which makes it suitable for observation under most optical microscopes. In our setup, the chamber was fastened to a stainless steel plate with stainless steel springs to hold the chamber in place. The plate was of the same dimensions as the standard Zeiss mounting frame, and could thus be positioned in its place and manipulated precisely by the object guide of the microscope.

Fig. 5 displays the components of the chamber and of a general experimental setup, and Fig. 6 shows the actual system as used in our experiment described in Section III-C. 


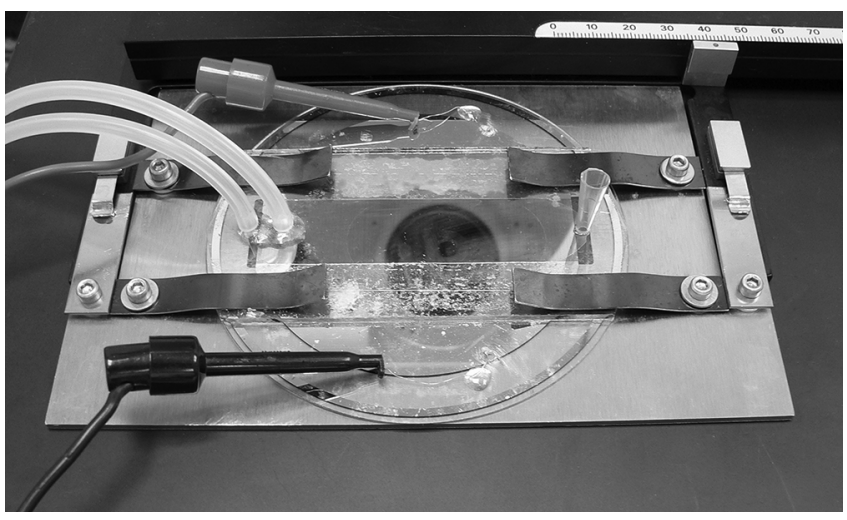

Fig. 6. The separation chamber connected to the syringes and to the electric field generator, and fixed on the mounting frame for observation under the microscope.

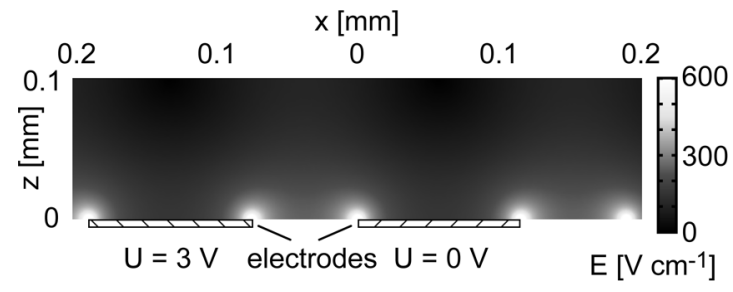

Fig. 7. Variation of $|E|$ along the channel with $115 \mu \mathrm{m}$ electrode width, 75 $\mu \mathrm{m}$ interelectrode gap, and $100 \mu \mathrm{m}$ channel height. The computations were performed in COMSOL Multiphysics.

\section{Selection of Electric Field Amplitude and Frequency}

At a given electrode width, interelectrode gap, and channel height, the dielectrophoretic force increases with the increase of electric field generated by the voltage between adjacent electrodes. Thus, a higher electric field provides a more efficient separation, but the highest field useful for this purpose is in general limited by the requirement that it should not affect the viability of the cells. Therefore, even at the close proximity to the electrodes, the field amplitude should remain below the values that cause cell membrane electroporation. The threshold value for this phenomenon is in the range of several hundred $\mathrm{V} / \mathrm{cm}$, depending on the cell size and shape [38], as well as cell type [39].

Fig. 7 shows the spatial distribution of $|\mathbf{E}|$ for the separation chamber with $115 \mu \mathrm{m}$ electrode width, $75 \mu \mathrm{m}$ interelectrode gap, $100 \mu \mathrm{m}$ channel height, and $3 \mathrm{~V}$ interelectrode voltage, which was built by our group and is described in more detail in subsequent paragraphs (the deviation of our $115 \mu \mathrm{m} / 75 \mu \mathrm{m}$ spacing from the ideal $100 \mu \mathrm{m} / 100 \mu \mathrm{m}$ spacing is due to the fabrication process). Fig. 7 shows that the maximum value of $|\mathbf{E}|$ in the channel is about $500 \mathrm{~V} / \mathrm{cm}$, which is below the electroporation threshold for sinewave fields acting on the $\mathrm{CHO}$ cells that were used to test this chamber (see Section III-C) [40]. For other cell types, the applied interelectrode voltage should be adjusted accordingly.

For successful field-flow separation, $f_{\mathrm{CM}}$ of at least one class of CHO cells (either normal, or heat-treated) must be negative, so that $F_{\mathrm{DEP}}$ is oriented upwards. Moreover, for the cells in this class to attain equilibrium heights above the bottom of the chamber, $F_{\mathrm{DEP}}$ at the bottom must exceed the effective gravitational force acting on the cells (i.e., the difference between the total gravitational force and the buoyancy force).

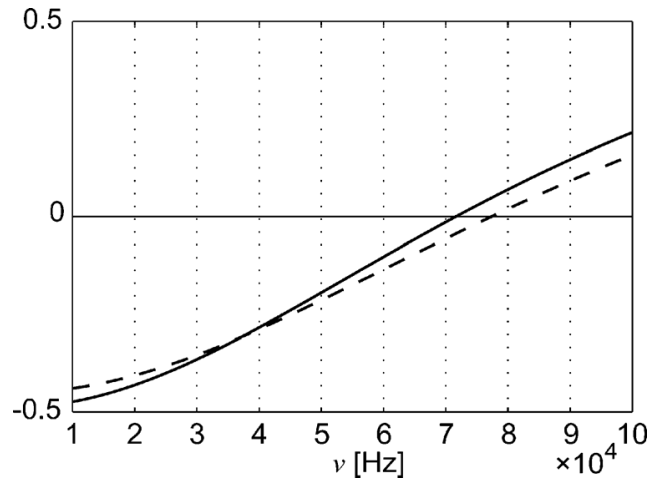

Fig. 8. The theoretically predicted dielectrophoretic spectra, $f_{\mathrm{CM}}(\nu)$, of normal (solid) and heat-treated (dashed) $\mathrm{CHO}$ cells in the phosphate buffer saline composed as described in Section II-E. The scale is linear for clearer distinction of the cross-over frequencies $(72 \mathrm{kHz}$ for normal cells, $78 \mathrm{kHz}$ for heat-treated cells).

To determine the electric field frequency for which these criteria are met, we estimated the dielectrophoretic spectra for normal and heat-treated CHO cells. These were obtained by inserting the values of the geometric and electric parameters of the $\mathrm{CHO}$ cells and the surrounding medium from Table I into (1)-(3), and are shown in Fig. 8. To ensure that $F_{\text {DEP }}$ acted upwards on at least one class of $\mathrm{CHO}$ cells despite possible deviations of actual parameter values from the assumed ones, we set the field frequency at $\nu=65 \mathrm{kHz}$. According to the spectra shown in Fig. 8, at $65 \mathrm{kHz} F_{\text {DEP }}$ would act upwards on both classes of cells, with the force on the heat-treated cells about $25 \%$ higher than on the normal ones. Under these conditions and assuming the cell density of $1072 \mathrm{~g} / \mathrm{cm}^{3}$ [16], the equilibrium between the dielectrophoretic and the effective gravitational force would be attained at about $42 \mu \mathrm{m}$ for heat-treated cells, and at about $29 \mu \mathrm{m}$ for normal ones. At the flow rate of $30 \mu \mathrm{l} / \mathrm{min}$, this would correspond to $0.41 \mathrm{~mm} / \mathrm{s}$ for heat-treated cells, and to $0.35 \mathrm{~mm} / \mathrm{s}$ for normal ones, so that over the $8 \mathrm{~cm}$ length of the channel the normal cells would accumulate a lag of about $12 \mathrm{~mm}$ behind the heat-treated ones. In this estimate, we assume that the velocity of the cells is equal to the velocity of the medium, which is based on theoretical considerations detailed in [41], [42].

\section{Cell Separation}

The efficiency of the separation chamber was tested by separation of viable cells and cells that were heat-treated only to the extent that they still retained their normal shape and appearance, losing only their long-term viability (see Section II-E). Thus, while typical heat-treatments are performed at temperatures over $80{ }^{\circ} \mathrm{C}$ [11], [12], [43], we only exposed the cells to $50{ }^{\circ} \mathrm{C}$.

The chamber was first filled with pure buffer, followed by an injection of a $30 \mu \mathrm{l}$ batch of the cell suspension $(1: 1$ mixture of viable and heat-treated cells in the buffer at a total $2 \times 10^{6}$ cells $/ \mathrm{ml}$ ), and followed again by pumping of pure buffer, all at a constant flow rate of $30 \mu \mathrm{l} / \mathrm{min}$. The first cells reached the output $4 \mathrm{~min}$ after their injection, and starting from that time, every minute the $30 \mu 1$ sample reaching the output was pipetted onto a separate microscope slide, and the cells were counted as described in Section II-F. After 16 min, most 


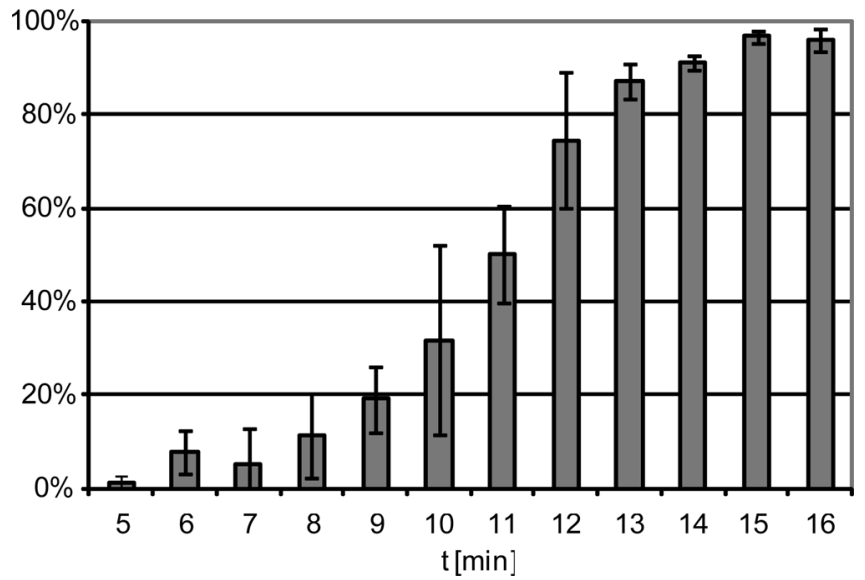

Fig. 9. Fraction of viable cells within the samples reaching the output of the separation chamber in one-minute sampling intervals ("5" represents the sample collected in the time interval from 4:01 to 5:00, etc.). The column heights give the mean values, and the error bars give the standard deviations of 4 independent experiments.

of the cells reached the output and the experiment was ended. The results are shown in Fig. 9, confirming the theoretical expectation that the non-viable cells reach the output first and viable cells later (see Section III-C).

By collecting the samples up to the 12th minute into one container, and all the later samples into a second one, the ratio of viable to nonviable cells would be $25 \%: 75 \%$ in the first container, and $93 \%: 7 \%$ in the second one. For many applications, the second ratio represents a satisfactory separation efficiency. It should be noted that separation efficiencies close to $100 \%$ reported in some experiments were obtained with cells heat-treated at temperatures ranging from $75^{\circ} \mathrm{C}$ to $90^{\circ} \mathrm{C}$ [11], [34], [43], and it is safe to assume that such cells differ from normal ones by a much larger extent than the cells heat-treated at $50{ }^{\circ} \mathrm{C}$ (as used here). Still, with optimization of the electric field frequency, flow rate, sampling intervals, etc., the separation efficiency obtained here could likely be improved further.

An additional experiment was performed by pumping the cell mixture through the chamber under the same conditions as above, but in the absence of the electric field. In this case, the ratio of viable and non-viable cells varied randomly through the subsequent samples, with no significant peak of either viable or non-viable cells in any of the samples. This implies that in the absence of the dielectrophoretic force, there is no significant difference between vertical positions of viable and nonviable cells within the channel, and that the dielectrophoretic force plays the main role in the separation process.

\section{CONCLUSIONS}

We have described a dielectrophoretic field-flow microchamber for separation of biological cells based on their electrical properties. The chamber design allows for simple assembly, use, disassembly, and cleaning. Its top and bottom surfaces are made of glass, making the events in the chamber observable under most optical microscopes, while the self-adhesive spacer positioned between them provides a tight seal and a fixed and controlled height of the separation channel. The channel volume of $160 \mu 1$ allows for separation of batches containing tens of thousands of cells, and for applications where such cell quantities per batch are acceptable, our test at a flow rate of $30 \mathrm{ul} / \mathrm{min}$ proved the chamber efficiency for separating cells with sufficient differences in electrical properties of their membranes. Still, unlike with continuous separation designs, which allow for online tuning of the electric field amplitude and frequency, in the approach presented here these two quantities have to be predetermined either based on theoretical modeling of the spectra, or by a series of optimization runs.

The capacity of separation could be increased by pumping the buffer through the channel at a higher flow rate. At least in principle, this could allow also for separation of cells in which the membrane electrical properties are altered only temporarily, e.g., due to membrane poration by electric field [44], ultrasound [45], or chemical agents (e.g., actinoporins [46] or detergents [5]). The separation efficiency under given experimental conditions could also be improved by optimization of the electric field frequency used for dielectrophoresis under those particular conditions. As a complement, the agreement between theoretical predictions and experimental results could perhaps be enhanced by expanding the single-shell model into a multi-shell one [30], allowing to model, e.g., also the role of the nucleus.

\section{REFERENCES}

[1] H. A. Pohl and J. S. Crane, "Dielectrophoresis of cells," Biophys. J., vol. 11, pp. 711-727, 1971

[2] H. Liu and H. Bau, "The dielectrophoresis of cylindrical and spherical particles submerged in shells and in semi-infinite media," Phys. Fluids, vol. 16, pp. 1217-1228, 2004.

[3] M. M. Meighan, S. J. R. Staton, and M. A. Hayes, "Bioanalytical separations using electric field gradient techniques," Electrophoresis, vol 30 , pp. 852-865, 2009 .

[4] D. Bakewell and H. Morgan, "Dielectrophoresis of DNA: Time- and frequency-dependent collections on microelectrodes," IEEE Trans. NanoBiosci., vol. 5, pp. 139-146, 2006.

[5] P. Patel and G. H. Markx, "Dielectric measurement of cell death," Enzyme Microb. Technol., vol. 43, pp. 463-470, 2008.

[6] H. O. Fatoyinbo, K. F. Hoeftges, and M. P. Hughes, "Rapid-on-chip determination of dielectric properties of biological cells using imaging techniques in a dielectrophoresis dot microsystem," Electrophoresis, vol. 29 , pp. 3-10, 2008

[7] F. Becker, X. Wang, Y. Huang, R. Pethig, J. Vykoual, and P. Gascoyne, "Separation of human breast-cancer cells from blood by differential dielectric affinity," Proc. Nat. Acad. Sci. USA, vol. 92, pp. 860-864, 1995.

[8] J. Voldman, "Electrical forces for microscale cell manipulation," Аnnu. Rev. Biomed. Eng., vol. 8, pp. 425-454, 2006.

[9] Y. Huang, X. B. Wang, F. F. Becker, and P. R. C. Gascoyne, "Introducing dielectrophoresis as a new force field for field-flow fractionation," Biophys. J., vol. 73, pp. 1118-1129, 1997.

[10] G. H. Markx, J. Rousselet, and R. Pethig, "DEP-FFF: Field-flow fractionation using non-uniform electric fields," J. Liq. Chromatogr. Related Technol., vol. 20, pp. 2857-2872, 1997.

[11] I. Doh and Y. H. Cho, "A continuous cell separation chip using hydrodynamic dielectrophoresis (DEP) process," Sens. Actuators A Phys, vol. 121, pp. 59-65, 2005.

[12] C. Iliescu, L. M. Yu, F. E. H. Tay, and B. T. Chen, "Bidirectional field-flow particle separation method in a dielectrophoretic chip with 3D electrodes," Sens. Actuators B, Chem., vol. 129, pp. 491-496, 2008.

[13] J. Suehiro, G. B. Zhou, M. Imamura, and M. Hara, "Dielectrophoretic filter for separation and recovery of biological cells in water," IEEE Trans. Ind. Appl., vol. 39, pp. 1514-1521, 2003.

[14] E. M. Nascimento, N. Nogueira, T. Silva, T. Braschler, N. Demierre, P. Renaud, and A. G. Oliva, "Dielectrophoretic sorting on a microfabricated flow cytometer: Label free separation of Babesia bovis infected erythrocytes," Bioelectrochemistry, vol. 73, pp. 123-128, 2008.

[15] X. Wang, J. Yang, Y. Huang, J. Vykoukal, F. F. Becker, and P. R. C. Gascoyne, "Cell separation by dielectrophoretic field-flow-fractionation," Anal. Chem., vol. 72, pp. 832-839, 2000. 
[16] J. Yang, Y. Huang, X. B. Wang, F. F. Becker, and P. R. C. Gascoyne, "Cell separation on microfabricated electrodes using dielectrophoretic/gravitational field flow fractionation," Anal. Chem., vol. 71, pp. 911-918, 1999.

[17] H. Zhou, L. R. White, and R. D. Tilton, "Lateral separation of colloids or cells by dielectrophoresis augmented by AC electroosmosis," J. Colloid Interface Sci., vol. 285, pp. 179-191, 2005.

[18] P. R. C. Gascoyne, X. B. Wang, Y. Huang, and F. F. Becker, "Dielectrophoretic separation of cancer cells from blood," IEEE Trans. Ind. Appl., vol. 33, pp. 670-678, 1997.

[19] G. D. Gasperis, J. Yang, F. F. Becker, P. R. C. Gascoyne, and X. Wang, "Microfluidic cell separation by 2-dimensional dielectrophoresis," Biomed. Microdevices, vol. 2, pp. 41-49, 1999.

[20] L. M. Yu, C. Iliescu, G. L. Xu, and F. E. H. Tay, "Sequential field-flow cell separation method in a dielectrophoretic chip with 3-D electrodes," J. Microelectromech. Syst., vol. 16, pp. 1120-1129, 2007.

[21] D. Holmes, N. G. Green, and H. Morgan, "Microdevices for dielectrophoretic flow-through cell separation," IEEE Eng. Med. Biol. Mag., vol. 22, pp. 85-90, 2003.

[22] C. D. Falokun, F. Mavituna, and G. H. Markx, "AC electrokinetic characterisation and separation of cells with high and low embryogenic potential in suspension cultures of carrot (Daucus carota)," Plant Cell Tiss. Org., vol. 75, pp. 261-272, 2003.

[23] G. H. Markx, R. Pethig, and J. Rousselet, "The dielectrophoretic levitation of latex beads, with reference to field-flow fractionation," J. Phys. D, Appl. Phys., vol. 30, p. 2470, 1997.

[24] N. Flores-Rodriguez and G. H. Markx, "Improved levitation and trapping of particles by negative dielectrophoresis by the addition of amphoteric molecules," J. Phys. D, Appl. Phys., vol. 37, pp. 353-361, 2004.

[25] J. Rousselet, G. H. Markx, and R. Pethig, "Separation of erythrocytes and latex beads by dielectrophoretic levitation and hyperlayer field-flow fractionation," Colloids Surf., A, vol. 140, pp. 209-216, 1998.

[26] F. Yang, X. M. Yang, H. Jiang, P. Bulkhaults, P. Wood, W. Hrushesky, and G. R. Wang, "Dielectrophoretic separation of colorectal cancer cells," Biomicrofluidics, vol. 4, p. 13, 2010.

[27] N. Pamme, "Continuous flow separations in microfluidic devices," Lab Chip, vol. 7, pp. 1644-1659, 2007.

[28] Comsol, COMSOL Multyphisics 3.5a User's Guide. Stockholm, Sweden, Comsol AB, 2008.

[29] Comsol, COMSOL Multyphisics 3.5a AC/DC Module User's Guide. Stockholm, Sweden, Comsol AB, 2008.

[30] T. B. Jones, "Basic theory of dielectrophoresis and electrorotation," IEEE Eng. Med. Biol. Mag., vol. 22, pp. 33-42, 2003.

[31] B. Alberts, A. Johnson, J. Lewis, M. Raff, K. Roberts, and P. Walter, Molecular Biology of the Cell, 4th ed. New York: Garland Sci., 2002.

[32] R. Buchner, G. T. Hefter, and P. M. May, "Dielectric relaxation of aqueous $\mathrm{NaCl}$ solutions," J. Phys. Chem. A, vol. 103, pp. 1-9, Jan. 1999.

[33] P. R. Gascoyne, R. Pethig, J. P. Burt, and F. F. Becker, "Membrane changes accompanying the induced differentiation of Friend murine erythroleukemia cells studied by dielectrophoresis," Biochim. Biophys. Acta., vol. 1149, pp. 119-126, Jun. 1993.

[34] Y. Huang, R. Hölzel, R. Pethig, and X. B. Wang, "Differences in the $\mathrm{AC}$ electrodynamics of viable and non-viable yeast cells determined through combined dielectrophoresis and electrorotation studies," Phys. Med. Biol., vol. 37, pp. 1499-1517, Jul. 1992.

[35] Q. Hu, R. P. Joshi, and A. Beskok, "Model study of electroporation effects on the dielectrophoretic response of spheroidal cells," J. Appl. Phys., vol. 106, p. 024701, 2009.

[36] R. Holzel and I. Lamprecht, "Dielectric-properties of yeast-cells as determined by electrorotation," Biochim. Biophys. Acta., vol. 1104, pp. 195-200, Feb. 1992.

[37] M. Ušaj, K. Trontelj, R. Hudej, M. Kandušer, and D. Miklavčič, “Cell size dynamics and viability of cells exposed to hypotonic treatment and electroporation for electrofusion optimization," Radiol. Oncol., vol. 43, pp. 108-119, 2009.

[38] B. Valic, M. Golzio, M. Pavlin, A. Schatz, C. Faurie, B. Gabriel, J. Teissie, M. Rols, and D. Miklavcic, "Effect of electric field induced transmembrane potential on spheroidal cells: Theory and experiment," Eur. Biophys. J., vol. 32, pp. 519-528, 2003.
[39] M. Cemazar, T. Jarm, D. Miklavcic, A. Lebar, A. Ihan, N. Kopitar, and G. Sersa, "Effect of electric-field intensity on electropermeabilization and electrosensitivity of various tumor-cell lines in vitro," ElectroMagnetobiol., vol. 17, pp. 263-272, 1998.

[40] T. Kotnik, G. Pucihar, M. Reberšek, D. Miklavčič, and L. M. Mir, "Role of pulse shape in cell membrane electropermeabilization," Biochim. Biophys. Acta., vol. 1614, pp. 193-200, 2003.

[41] A. Castellanos, A. Ramos, A. Gonzalez, N. G. Green, and H. Morgan, "Electrohydrodynamics and dielectrophoresis in microsystems: Scaling laws," J. Phys. D, Appl. Phys., vol. 36, pp. 2584-2597, 2003.

[42] B. Weiss, W. Hilber, P. Gittler, and B. Jakoby, "Particle separation in alternating-current electro-osmotic micropumps using field-flow fractionation," Microfluid. Nanofluid., vol. 7, pp. 191-203, 2009.

[43] H. B. Li and R. Bashir, "Dielectrophoretic separation and manipulation of live and heat-treated cells of Listeria on microfabricated devices with interdigitated electrodes," Sens. Actuators B, Chem., vol. 86, pp. 215-221, 2002.

[44] G. Pucihar, T. Kotnik, D. Miklavcic, and J. Teissie, "Kinetics of transmembrane transport of small molecules into electropermeabilized cells," Biophys. J., vol. 95, pp. 2837-2848, 2008.

[45] Y. Zhou, J. Shi, J. Cui, and C. X. Deng, "Effects of extracellular calcium on cell membrane resealing in sonoporation," J. Controlled Release, vol. 126, pp. 34-43, 2008.

[46] K. Kristan, Z. Podlesek, V. Hojnik, I. Gutiérrez-Aguirre, G. Gunčar, D. Turk, J. M. González-Mañas, J. H. Lakey, P. Maček, and G. Anderluh, "Pore formation by equinatoxin, A eukaryotic pore-forming toxin, requires a flexible $\mathrm{N}$-terminal region and a stable $\beta$-sandwich," J. Biol. Chem., vol. 279, pp. 46509-46517, 2004.

Jaka Čemažar received the B.Sc. degree in electrical engineering from the University of Ljubljana, Slovenia, in 2008, where he is currently working toward the Ph.D. degree.

His main research interest is design of microdevices for separation of biological cells.

Danilo Vrtačnik received the Ph.D. in electrical engineering from the University of Ljubljana, Slovenia, in 2000.

Since 2007 he has been a Higher Scientific Associate at the Laboratory of Microsensor Structures, Faculty of Electrical Engineering, University of Ljubljana. His current research interests include development of silicon radiation detectors and related photodevices as well as advanced sensors and actuator structures fabricated by microelectromechanical systems (MEMS) technologies.

Slavko Amon (M'75) received the Ph.D. degree in electrical engineering from the University of Ljubljana, Slovenia, in 1981.

Since 1992 he has been a Full Professor on the Faculty of Electrical Engineering, University of Ljubljana, where he is also the Head of the Laboratory of Microsensor Structures. His current research interests include micro-/nanomicroelectromechanical systems (nano-MEMS) structures and technologies, micromachining, modeling, and new microsensor and microactuator structures. $\mathrm{He}$ was a reviewer for international journals.

Tadej Kotnik received the Ph.D. degree in electrical engineering from the University of Ljubljana, Slovenia, and the Ph.D. degree in biophysics from University Paris XI, France, both in 2000.

Since 2001 he has been an Assistant Professor on the Faculty of Electrical Engineering, University of Ljubljana, where he is also a Higher Scientific Associate in the Laboratory of Biocybernetics. His current research interests include membrane electrodynamics and related biophysical phenomena (particularly membrane electroporation), as well as computational research in number theory. 